\title{
Nocturia and Sleep: Focus on Common Comorbidities and Their Association with Obstructive Sleep Apnea
}

\author{
Yoo Hyun Um, MD, PhD, Ji-Hye Oh, MD, Tae-Won Kim, MD, Ho-Jun Seo, MD, PhD, Sung-Min Kim, MD, \\ Jun-Soo Chung, MD, Jong-Hyun Jeong, MD, PhD, Seung-Chul Hong, MD, PhD \\ Department of Psychiatry, College of Medicine, The Catholic University of Korea, Seoul, Korea
}

Received: October 16, 2020

Revised: November 12, 2020

Accepted: December 1, 2020

Correspondence

Seung-Chul Hong, MD, PhD

Department of Psychiatry,

St. Vincent's Hospital, College of Medicine,

The Catholic University of Korea,

93 Jungbu-daero, Paldal-gu,

Suwon 16247, Korea

Tel +82-31-249-7114

Fax +82-31-248-6758

E-mail hscjohn@hotmail.com

\section{ORCID}

Yoo Hyun Um

https://orcid.org/0000-0002-3403-4140 Ji-Hye Oh

https://orcid.org/0000-0002-6865-3935

Tae-Won Kim

https://orcid.org/0000-0003-2689-202X

Ho-Jun Seo

https://orcid.org/0000-0003-1661-1394

Sung-Min Kim

https://orcid.org/0000-0002-3082-4014

Jun-Soo Chung

https://orcid.org/0000-0003-3641-7804

Jong-Hyun Jeong

https://orcid.org/0000-0003-3570-7607

Seung-Chul Hong

https://orcid.org/0000-0003-0828-2906

(C) This is an Open Access article distributed under the terms of the Creative Commons Attribution Non-Commercial License (https://creativecommons.org/licenses/by-nc/4.0) which permits unrestricted non-commercial use, distribution, and reproduction in any medium, provided the original work is properly cited.
Nocturia is a frequently encountered complaint in patients visiting sleep clinics. Nocturia and its detrimental effect on sleep continuity and quality have been frequently discussed in previous studies. Moreover, abundant research has been conducted to delineate the close relationship between nocturia and the pathophysiology of obstructive sleep apnea (OSA). In this review, we discuss the common comorbidities that can provoke nocturia and their relationship with OSA and sleep.

Sleep Med Res 2020;11(2):59-64

Key Words Nocturia, Sleep, Obstructive sleep apnea, Comorbidity.

\section{INTRODUCTION}

Nocturia is a lower urinary-tract symptom (LUTS) that is defined by the International Continence Society as the sensations to void one or more time during the night [1]. It is closely related to sleep problems [2], and the bidirectionality of the link between sleep and nocturia is often discussed [3]. The prevalence of nocturia has been reported to be $11 \%$ to $35.2 \%$ in men aged 20-40 years, but notably escalated prevalence rates are evident in the elderly population, with rates ranging from $68.9 \%$ to $93 \%$ [4]. In an internet-based survey on the general population aged $\geq 40$ years, prevalence of nocturia was $76.1 \%$ for women and $74.0 \%$ for men [5]. Nocturia is a clinically notable culprit for sleep problems, with reports of a significantly proportional increase in the number of nocturnal voids and a close correlation with poorer sleep quality [6]. Moreover, detrimental effects on daytime functions and increased prevalence of excessive daytime sleepiness were noted in patients with nocturia [6,7]. Furthermore, it is usually a challenge for sleep specialists to evaluate whether nocturia precedes insomnia or vice versa. The exact mechanisms underlying the bidirectionality between the two clinical constructs remain elusive. Despite its clinical importance, history taking, proper evaluation, and management of nocturia are frequently dismissed by sleep clinicians. In explaining the association between sleep and nocturia, much of the recent evidence has centered on the relationship between obstructive sleep apnea (OSA) and sleep. Indeed, mounting evidence emphasizes nocturia as an important clinical indicator of OSA. Increments in intra-abdominal pressure, increased atrial natriuretic peptide secretions, and arousals due to OSA may be mechanisms that result in nocturia and resultant poor sleep quality (Fig. 1) [8]. We will mainly discuss common comorbid conditions of nocturia that clinicians face in clinical settings and their relationships to sleep and OSA. 


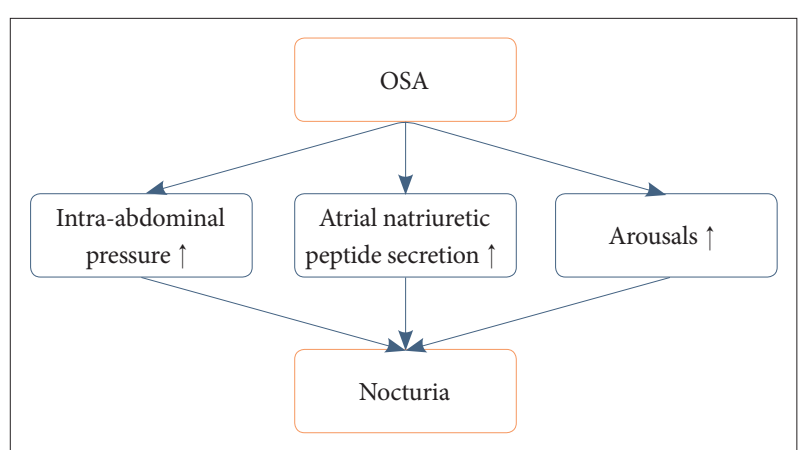

Fig. 1. The pathophysiological mechanism underlying OSA and nocturia [8]. OSA: obstructive sleep apnea.

\section{COMMON COMORBID CONDITIONS OF NOCTURIA AND THEIR RELATIONSHIPS TO SLEEP AND OSA}

\section{OSA, Nocturia, and Sleep}

The relationships between OSA, nocturia, and resultant sleep disturbance have been reported in many previous studies. The purported mechanism for the frequent nocturia observed in OSA patients is hypoxia induced by OSA and the resultant sequential events of negative pressure breathing and atrial natriuretic peptide secretion, which ultimately lead to nocturia episodes [9]. In a recent meta-analysis on the relationship between OSA and nocturia, there was a 1.5-fold increase in the risk of nocturia in men, but no significant relationship was noted in women [10]. According to the aforementioned meta-analysis, such a risk was not changed by the methods implemented to diagnose OSA [10]. Indeed, when assessed with the Berlin Questionnaire, there was an approximately 3-fold increase in the events classified as high risk of OSA in the nocturia group over those for the controls [11]. Another report with polysomnography (PSG) data reported a higher risk, with a 2.4-fold increase of incidence of severe OSA in patients with a nocturia history [12].

Moreover, interestingly, one study reported that nocturia might be as sensitive as snoring or body mass index (BMI) in the prediction of OSA [13]. One recent study suggested that OSA patients with nocturia represented a clinically severe OSA phenotype, with higher apnea-hypopnea index, more severe excessive daytime sleepiness, lower nadir oxygen levels, and higher BMI [12]. Another study reported a linear increase in the severity of OSA with the frequency of nocturia [14]. Another study recommended further urological evaluation in OSA patients with fewer compromised oxygen desaturation events even after correction for OSA [15]. Moreover, interestingly, not the severity or length of hypoxia but the intermittent desaturation events were predictive of nocturia incidence in sleep disordered breathing (SDB) patients in one study [16], probably because the respiratory efforts to compensate for limited airflow lead to increments in abdominal pressure that induce nocturia [16].

In the findings that attest to the fixed relationship between nocturia and OSA, the effectiveness of continuous positive airway pressure (CPAP) in relieving nocturia has been replicated. With one-year treatment of CPAP, most urologic parameters, including nocturia episodes, nocturnal polyuria prevalence, and detrusor overactivity all demonstrated significant improvements [17]. CPAP effectively improved daytime sleepiness, depression, and quality of life in OSA patients with nocturia $[18,19]$. Nocturia frequency decreased in terms of urine volume, which largely affected quality of life in OSA patients [20]. More significantly, nocturia was predictive of hypertension in OSA patients, and CPAP therapy was recommended as relieving both nocturia and hypertension in one study [21]. SDB patients with nocturia who were responsive to CPAP therapy all showed positive outcomes, with decreased systolic blood pressure B-type natriuretic peptide [22]. More studies are pointing to the importance of the relationship between coronary heart disease and nocturia [23]. Thus, nocturia in OSA patients should not be underdiagnosed in clinical settings, considering its importance in the prevention and management of cardiovascular diseases.

\section{Benign Prostate Hyperplasia: Relationship to Nocturia, Sleep, and OSA}

Patients with benign prostate hyperplasia $(\mathrm{BPH})$ were prone to complain of poorer sleep quality, which was proportionally worsened by nocturia episodes [24]. One PSG result on 20 patients with $\mathrm{BPH}$ demonstrated that $\mathrm{BPH}$ patients experienced nocturia mostly during superficial sleep stages or rapid eye-movement sleep [25]. Nocturia in BPH patients was significantly associated with excessive daytime sleepiness [25], probably because sleep continuity can be disrupted by nocturia [26]. Severe insomnia and poor sleep quality were noted in $\mathrm{BPH}$ patients who experienced frequent nocturia episodes [24,27].

A single-therapy group of tamsulosin hydrochloride, an alpha-1-blocker, and a combination-therapy group of tamsulosin hydrochloride and meloxicam, a cyclooxygenase inhibitor-2, were compared to evaluate their effectiveness in improving sleep quality in BPH patients with nocturia [28]. The combination therapy significantly decreased episodes of nocturia and improved sleep quality [28]. Melatonin helped BPH patients with nocturia by reducing habitual mid-night awakenings [29]. Another study on patients with LUTS suggestive of BPH demonstrated that those who were refractory to alpha-1 antagonist therapy, when it was combined with ramelteon, a melatonin 1 and 2 agonist, had their nocturia episodes significantly reduced without adverse events [30]. Moreover, $\mathrm{BPH}$ patients with partial remission of nocturia when receiving tamsulosin (alpha-1 antagonist) were responsive to combination therapy with zolpidem. Zolpidem's effect on nocturia and sleep was implemented not only by exerting its gamma-amnobutyric acid (GABA)-ergic effect on sleep induction but also by suppression of urine excretion [31]. BPH patients after surgical intervention, usually transurethral resection of the prostate, experienced alleviation of sleep disturbances and noc- 
turia [32]. Patients with residual symptoms after transurethral resection tended to have voiding and storage problems [32].

In patients with $\mathrm{BPH}$, frequency of nocturia was proportionally increased with the odds of having symptoms of OSA [33]. $\mathrm{BPH}$ with frequent nocturia episodes should be evaluated for OSA. Moreover, one study also reported that BPH patients with storage symptoms were highly likely to have OSA [34]. In a study that evaluated the relationship between CPAP adherence and nocturia episodes in $\mathrm{BPH}$ patients, there was no significant relationship between the two [35]. It was assumed that disconnection of the mask because of nocturia would affect CPAP adherence, but that pattern was not as evident in $\mathrm{BPH}$ patients who perceived therapeutic benefits from CPAP therapy [35].

\section{Overactive Bladder: Relationship with Nocturia, Sleep, and OSA}

Recent literature demonstrates the importance of understanding the relationship between overactive bladder $(\mathrm{OAB})$, nocturia, and sleep, since nocturia is the most common LUTS of OAB [36]. According to one study on $\mathrm{OAB}$ symptoms in 150 women, the most frequent complaint was "strong desire to void," with mean nocturia episodes of 4.5 [37]. All women with OAB and nocturia complained of insomnia [38], and another study found that sleep disturbances and fatigue were evident in most OAB patients, with such complaints linearly increasing with severity of OAB symptoms [39]. Decreased quality of life and significant sleep disturbances were observed especially in $\mathrm{OAB}$ patients who awaken more than twice during the night [40]. When compared with insomnia patients, $\mathrm{OAB}$ patients tended to wake up at night with shorter duration, because of a strong urge to void at night [41]. OAB symptoms frequently result in urgent urinary incontinence, which can lead to poor sleep quality and excessive daytime sleepiness [42].

An effective treatment can benefit $O A B$ patients to a significant degree, with improvements in sleep parameters [43]. Mirabegron, a beta-3 adrenoreceptor agonist, was reported to be efficacious, with a relatively safe drug profile, in elderly patients with OAB [44]. Desmopressin can also be used, but caution is needed in patients at risk of hyponatremia [44]. For those with nocturnal urgent urinary incontinence, which stems from the imbalance between bladder capacity and nocturnal urinary production, fesosterodine, an antimuscarinic drug, has been recommended for the alleviation of symptoms [45]. A dose of $4 \mathrm{mg}$ of fesosterodine was effective in increasing sleep continuity when compared with that of controls [46]. Treatment of urgent urinary incontinence is critically important in $\mathrm{OAB}$ patients. There has been a report where pharmacological intervention in urgent urinary incontinence patients substantially improved sleep quality, duration, and efficiency [47]. Solifenacin, another competitive antimuscarinic drug, was effective in relieving sleep disturbance, not by decreasing nocturia episodes but by reducing urgency [48]. An oxybutynin patch, with its once-daily antimuscarinic property, was tested for efficacy in OAB patients [36]. When compared with controls, $\mathrm{OAB}$ patients with an oxybutynin patch showed fewer nocturia episodes and increased sleep continuity, which improved sleep-related quality of life [36].

The relationship between OSA, OAB, and nocturia has been discussed in some of the literature [49]. OSA is well known for its relationship to erectile dysfunction and nocturia. Severity of OSA was proportional to $\mathrm{OAB}$ and urinary incontinence occurrence [50]. A diluted nocturnal urine was predictive of OSA diagnosis, with $88 \%$ of sensitivity in patients with daytime OAB symptoms [51], which were more severe in the OSA group than in the control group [52]. Proposed mechanisms for the aforementioned relationship include the intermittent hypoxia induced by OSA; this oxidative stress changes the bladder structurally and functionally [53]. Indeed, bladder-wall thickness and OAB symptoms were closely related in OSA patients [52]. However, one study found no increased prevalence of $\mathrm{OAB}$, nocturia, or urgent urinary incontinence symptoms in young male patients with OSA [54]. Further studies are warranted for the early diagnosis of OSA in $\mathrm{OAB}$ patients with nocturia and urgent urinary incontinence.

\section{Diabetes Mellitus: Relationship with Nocturia, Sleep and OSA}

Most literature on diabetes mellitus (DM) and nocturia is on type $2 \mathrm{DM}$, on which the following paragraphs will mostly focus. In a Japanese study that included 332 male type 2 DM patients, approximately $80 \%$ of the participants complained of nocturia [55]. In a recent study on type 2 DM patients, older age, increased hemoglobin A1c level, lower extremity edema, and peripheral neuropathy predicted nocturia [56]. Exact mechanisms for this finding have not been fully elucidated. In a relatively large study on 1301 type $2 \mathrm{DM}$ patients, comorbid OAB was a predictor of nocturia with the highest odds, and type $2 \mathrm{DM}$ patients with nocturia had a higher death rate, even allowing for age and DM duration [57].

Those with higher nocturia frequency showed higher hemoglobin A1c levels, an indication of poorer glycemic control [56]. In a study on 275 type $2 \mathrm{DM}$ patients, those with nocturia complained of poorer sleep quality [58]. Poor glycemic control in type $2 \mathrm{DM}$ patients experiencing nocturia might be attributable to poor sleep quality induced by nocturia episodes. A previous study accentuated the importance of sleep deprivation in the induction of obesity and resultant harmful effects on glycemic control [59]. Moreover, one study suggested that delaying time to first voiding during the night can significantly reduce blood glucose in type 2 DM patients [60]. Furthermore, sleep fragmentation induced by nocturia can increase the next-day fatigue and resultant sedentary activities, which can worsen glycemic control [61].

Meanwhile, as mentioned above, nocturia is an important clinical marker that strongly represents the diagnosis of OSA; hence 
nocturia in type $2 \mathrm{DM}$ patients should not be dismissed. Indeed, a bidirectional relationship between OSA and type 2 DM has been replicated in previous studies. OSA can increase the incidence of type $2 \mathrm{DM}$ with its worsening of glucose metabolism, and type $2 \mathrm{DM}$ can increase the incidence of OSA because of diabetic neuropathy, which can perniciously affect respiratory control and upper airway reflexes [62,63]. Although some studies recommend CPAP for type 2 DM with OSA patients [64, 65], recent systematic reviews and meta-analyses present rather a disheartening result on the efficacy of CPAP on glycemic control of type $2 \mathrm{DM}$ patients [66]. Still, considering the harmful effects of OSA on the clinical course of type $2 \mathrm{DM}$, it is essential to further evaluate for OSA diagnosis in those presenting with nocturia.

\section{Depression: Relationship to Nocturia, Sleep, and OSA}

Previous literature reported a close link between depression and nocturia. Major depression increased the odds of nocturia 6-fold, with proposed mechanisms involving disturbed antidiuretic hormone secretion and changes of CNS monoamine concentrations that can induce $\mathrm{OAB}$, decrease reflex bladder contractions, and raise the bladder volume threshold [67]. Nocturia was not associated with the severity of depression, but there was a clear correlation between sleep quality and nocturia in patients with depression [68]. A bidirectional relationship also exists between depression and nocturia, with a report where LUTS including nocturia, when continued long term, can cause depression and anxiety [69].

Patients with depression on antidepressant medication should be asked about symptoms of nocturia. Even after controlling for depression, treatment with a selective serotonin reuptake inhibitor (SSRI) significantly increased the odds of nocturia [70]. Different classes of antidepressants can result in disparate prevalence of nocturia. One study reported a divergent result of nocturnal urinary frequency between those on SSRIs and those on noradrenaline reuptake inhibitors (NRI), with patients on SSRI reporting higher nocturnal urinary frequency than did those on NRI [71]. Moreover, compared with duloxetine, frequency increased 3-fold in the sertraline group [71]. These results arise from different drugs and side-effect profiles, but because nocturia increases depression and affects sleep quality in depressed patients, it is advisable to keep close surveillance of symptoms of nocturia in patients with depression.

Patients with both depressive symptoms and nocturia should always be asked for their sleep history and signs of OSA, since symptoms of OSA can mimic those of depression. About a quarter of male OSA patients reported low libido and had more nocturia events [72]. In a study where excessive daytime sleepiness exceeded the Epworth Sleepiness Scale, excessive daytime sleepiness was significantly associated with OSA severity and depression [73]. In a patient group with atypical depression, hypersom- nia is often a presenting symptom. It is necessary to differentiate hypersomnia from excessive daytime sleepiness and to expand the assessment to include sleep-history taking and OSA diagnosis.

\section{CONCLUSION}

When a patient presents with symptoms of nocturia and sleep disturbance, a clinician should search for common comorbidities that can induce nocturia. Moreover, it is important to understand the bidirectionality of those common comorbidities and nocturia. Since severity of nocturia is closely related to sleep disturbance, clinicians should look for appropriate treatments that consider the common comorbidities addressed in this review, not focusing only on the sleep problem itself. Furthermore, nocturia as a core symptom of OSA should not be dismissed in clinical settings, since many comorbidities of nocturia have a close association with OSA.

\section{Acknowledgments}

This work was supported by the National Research Foundation of Korea (NRF) grant funded by the Korean government (MSIT) (No. 2018R1D1A1 A02049615).

\section{Conflicts of Interest}

The authors have no financial conflicts of interest.

\section{Authors' Contribution}

Conceptualization: Um YH, Hong SC. Funding acquisition: Um YH. Project administration: Um YH, Hong SC. Supervision: Jeong JH, Seo HJ, Kim TW. Validation: Kim SM, Oh JH, Chung JS. Writing-original draft: Um YH. Writing—review \& editing: Um YH, Hong SC.

\section{REFERENCES}

1. van Kerrebroeck P, Abrams P, Chaikin D, Donovan J, Fonda D, Jackson S, et al. The standardisation of terminology in nocturia: report from the Standardisation Sub-committee of the International Continence Society. Neurourol Urodyn 2002;21:179-83.

2. Furtado D, Hachul H, Andersen ML, Castro RA, Girão MB, Tufik S. Nocturia×disturbed sleep: a review. Int Urogynecol J 2012;23:255-67.

3. Araujo AB, Yaggi HK, Yang M, McVary KT, Fang SC, Bliwise DL. Sleep related problems and urological symptoms: testing the hypothesis of bidirectionality in a longitudinal, population based study. J Urol 2014; 191:100-6.

4. Bosch JL, Weiss JP. The prevalence and causes of nocturia. J Urol 2013; 189:S86-92.

5. Chow PM, Liu SP, Chuang YC, Lee KS, Yoo TK, Liao L, et al. The prevalence and risk factors of nocturia in China, South Korea, and Taiwan: results from a cross-sectional, population-based study. World J Urol 2018;36:1853-62.

6. Shao IH, Wu CC, Hsu HS, Chang SC, Wang HH, Chuang HC, et al. The effect of nocturia on sleep quality and daytime function in patients with lower urinary tract symptoms: a cross-sectional study. Clin Interv Aging 2016;11:879-85.

7. Martin SA, Appleton SL, Adams RJ, Taylor AW, Catcheside PG, Vakulin A, et al. Nocturia, other lower urinary tract symptoms and sleep dysfunction in a community-dwelling cohort of men. Urology 2016;97: 219-26.

8. Ben Mansour A, Zaibi H, Ben Ammar J, Dahri B, Baccar MA, Azzabi 
S, et al. Prevalence of nocturia in obstructive sleep apnea syndrom. Eur Respir J 2015;46:PA2380.

9. Umlauf MG, Chasens ER, Greevy RA, Arnold J, Burgio KL, Pillion DJ. Obstructive sleep apnea, nocturia and polyuria in older adults. Sleep 2004;27:139-44.

10. Zhou J, Xia S, Li T, Liu R. Association between obstructive sleep apnea syndrome and nocturia: a meta-analysis. Sleep Breath 2020;24:1293-8.

11. Zebede S, Lovatsis D, Alarab M, Drutz H. Prevalence of obstructive sleep apnea detected by the Berlin Questionnaire in patients with nocturia attending a urogynecology unit. Int Urogynecol J 2015;26:881-5.

12. Goyal A, Pakhare A, Chaudhary P. Nocturic obstructive sleep apnea as a clinical phenotype of severe disease. Lung India 2019;36:20-7.

13. Romero E, Krakow B, Haynes P, Ulibarri V. Nocturia and snoring: predictive symptoms for obstructive sleep apnea. Sleep Breath 2010;14: 337-43.

14. Kaynak H, Kaynak D, Oztura I. Does frequency of nocturnal urination reflect the severity of sleep-disordered breathing? J Sleep Res 2004;13: 173-6.

15. Chung JH, Moon HS, Park SY, Kim KR, Cho SH, Kim YT. Effect of nocturnal hypoxia on nocturia in patients with obstructive sleep apnea. Int Neurourol J 2019;23:161-8.

16. Finamore P, Scarlata S, Laudisio A, Galdi F, Pipita ME, Chiarella I, et al. Occurrence of nocturia is not mediated by nocturnal hypoxia length and severity in patients with sleep-disordered breathing. Sleep Med 2018;45:69-73.

17. Fernández-Pello S, Gil R, Escaf S, Rodríguez Villamil L, Alzueta A, Rodríguez $\mathrm{C}$, et al. Lower urinary tract symptoms and obstructive sleep apnea syndrome: urodynamic evolution before and after one year of treatment with continuous positive airway pressure. Actas Urol Esp 2019;43:371-7.

18. Guilleminault C, Lin CM, Gonçalves MA, Ramos E. A prospective study of nocturia and the quality of life of elderly patients with obstructive sleep apnea or sleep onset insomnia. J Psychosom Res 2004;56:511-5.

19. İrer B, Çelikhisar A, Çelikhisar H, Bozkurt O, Demir Ö. Evaluation of sexual dysfunction, lower urinary tract symptoms and quality of life in men with obstructive sleep apnea syndrome and the efficacy of continuous positive airway pressure therapy. Urology 2018;121:86-92.

20. Miyauchi $Y$, Okazoe H, Okujyo M, Inada F, Kakehi T, Kikuchi H, et al. Effect of the continuous positive airway pressure on the nocturnal urine volume or night-time frequency in patients with obstructive sleep apnea syndrome. Urology 2015;85:333-6.

21. Destors M, Tamisier R, Sapene M, Grillet Y, Baguet JP, Richard P, et al. Nocturia is an independent predictive factor of prevalent hypertension in obstructive sleep apnea patients. Sleep Med 2015;16:652-8.

22. Miyazaki T, Kojima S, Yamamuro M, Sakamoto K, Izumiya Y, Tsujita $\mathrm{K}$, et al. Nocturia in patients with sleep-disordered breathing and cardiovascular disease. Circ J 2015;79:2632-40.

23. Weiss JP, Monaghan TF, Epstein MR, Lazar JM. Future considerations in nocturia and nocturnal polyuria. Urology 2019;133S:34-42.

24. Doo SW, Lee HJ, Ahn J, Kim JH, Yun JH, Yang WJ, et al. Strong impact of nocturia on sleep quality in patients with lower urinary tract symptoms. World J Mens Health 2012;30:123-30.

25. Bal K, Ayik S, Issi Y, Bolukbasi A, Akhan G. Sleep analysis of patients with nocturia and benign prostatic obstruction. Urology 2012;80:383-8.

26. Chartier-Kastler E, Leger D, Comet D, Haab F, Ohayon MM. Prostatic hyperplasia is highly associated with nocturia and excessive sleepiness: a cross-sectional study. BMJ Open 2012;2:e000505.

27. Chartier-Kastler E, Leger D, Montauban V, Comet D, Haab F. [Impact of nocturia on sleep efficiency in patients with benign prostatic hypertrophy]. Prog Urol 2009;19:333-40.

28. Gorgel SN, Sefik E, Kose O, Olgunelma V, Sahin E. The effect of combined therapy with tamsulosin hydrochloride and meloxicam in patients with benign prostatic hyperplasia symptoms and impact on nocturia and sleep quality. Int Braz J Urol 2013;39:657-62.

29. Drake MJ, Mills IW, Noble JG. Melatonin pharmacotherapy for noctu- ria in men with benign prostatic enlargement. J Urol 2004;171:1199202.

30. Kawahara T, Morita S, Ito H, Terao H, Sakata R, Ishiguro H, et al. Ramelteon combined with an a1-blocker decreases nocturia in men with benign prostatic hyperplasia. BMC Urol 2013;13:30.

31. Yokoyama O, Matsuta Y, Yanai-Inamura H, Watanabe M, Ohtake A, Suzuki M, et al. Zolpidem increases bladder capacity and decreases urine excretion in rats. Neurourol Urodyn 2010;29:587-91.

32. Wada N, Numata A, Hou K, Watanabe M, Kita M, Matsumoto S, et al. Nocturia and sleep quality after transurethral resection of the prostate. Int J Urol 2014;21:81-5.

33. Tandeter H, Gendler S, Dreiher J, Tarasiuk A. Nocturic episodes in patients with benign prostatic enlargement may suggest the presence of obstructive sleep apnea. J Am Board Fam Med 2011;24:146-51.

34. Arslan B, Gezmis CT, Çetin B, Gönültas S, Gökmen E, Gürkan O, et al. Is obstructive sleep apnea syndrome related to nocturia? Low Urin Tract Symptoms 2019;11:139-42.

35. Metta RV, Zaka A, Lee VC, Mador MJ. Continuous positive airway pressure adherence in patients with obstructive sleep apnea \& symptomatic BPH. Lung 2017;195:255-61.

36. Yokoyama O, Yamaguchi A, Yoshida M, Yamanishi T, Ishizuka O, Seki $\mathrm{N}$, et al. Once-daily oxybutynin patch improves nocturia and sleep quality in Japanese patients with overactive bladder: post-hoc analysis of a phase III randomized clinical trial. Int J Urol 2015;22:684-8.

37. Abu Mahfouz I, Asali F, Abdel-Razeq R, Ibraheem R, Abu Mahfouz S, Jaber $\mathrm{H}$, et al. Bladder sensations in women with nocturia due to overactive bladder syndrome. Int Urogynecol J 2020;31:1041-8.

38. Drake NL, Flynn MK, Romero AA, Weidner AC, Amundsen CL. Nocturnal polyuria in women with overactive bladder symptoms and nocturia. Am J Obstet Gynecol 2005;192:1682-6.

39. Ge TJ, Vetter J, Lai HH. Sleep disturbance and fatigue are associated with more severe urinary incontinence and overactive bladder symptoms. Urology 2017;109:67-73.

40. Newman DK, Koochaki PE. Characteristics and impact of interrupted sleep in women with overactive bladder. Urol Nurs 2011;31:304-12.

41. Preud'homme XA, Amundsen CL, Webster GD, Krystal AD. Comparison of diary-derived bladder and sleep measurements across $\mathrm{OAB}$ individuals, primary insomniacs, and healthy controls. Int Urogynecol J 2013;24:501-8.

42. Winkelman WD, Warsi A, Huang AJ, Schembri M, Rogers RG, Richter HE, et al. Sleep quality and daytime sleepiness among women with urgency predominant urinary incontinence. Female Pelvic Med Reconstr Surg 2018;24:76-81.

43. Chin KS, Rose GE, Ervin CF, Ong TJ, Whishaw DM, Bower WF. Does successful treatment of overactive bladder improve co-morbidities in patients with nocturia? Australas J Ageing 2019;38:242-8.

44. Chen JL, Chen SF, Jiang YH, Kuo HC. Practical points in the medical treatment of overactive bladder and nocturia in the elderly. Ci Ji Yi Xue Za Zhi 2016;28:1-5.

45. Khusid JA, Weiss JP, Carlsson MO, Mangan EK. Fesoterodine for the treatment of nocturnal urgency in patients with overactive bladder syndrome: an analysis of responders and nonresponders. J Urol 2017;198: 1119-23.

46. Yokoyama O, Hiro S, Hotta S, Mogami S, Yamagami H. Efficacy of fesoterodine on nocturia and quality of sleep in Asian patients with overactive bladder. Urology 2014;83:750-5.

47. Warsi QA, Huang AJ, Hess R, Arya LA, Richter HE, Bradley CS, et al. Association of pharmacologic treatment of urgency urinary incontinence with sleep quality and daytime sleepiness. Obstet Gynecol 2018; 131:204-11.

48. Takao T, Tsujimura A, Yamamoto K, Fukuhara S, Nakayama J, Matsuoka Y, et al. Solifenacin may improve sleep quality in patients with overactive bladder and sleep disturbance. Urology 2011;78:648-52.

49. Kemmer $\mathrm{H}$. The relationship between sleep apnea and overactive bladder. Curr Urol Rep 2009;10:448-50. 
50. Kemmer H, Mathes AM, Dilk O, Gröschel A, Grass C, Stöckle M. Obstructive sleep apnea syndrome is associated with overactive bladder and urgency incontinence in men. Sleep 2009;32:271-5.

51. Lowenstein L, Kenton K, Brubaker L, Pillar G, Undevia N, Mueller ER, et al. The relationship between obstructive sleep apnea, nocturia, and daytime overactive bladder syndrome in women. Am J Obstet Gynecol 2008;198:598.e1-5.

52. Yilmaz Z, Voyvoda B, Şirinocak PB. Overactive bladder syndrome and bladder wall thickness in patients with obstructive sleep apnea syndrome. Int Braz J Urol 2018;44:330-7.

53. Witthaus MW, Nipa F, Yang JH, Li Y, Lerner LB, Azadzoi KM. Bladder oxidative stress in sleep apnea contributes to detrusor instability and nocturia. J Urol 2015;193:1692-9.

54. Tuncer M, Yazici O, Kafkasli A, Sabuncu K, Salepci B, Narter F, et al. Critical evaluation of the overactive bladder and urgency urinary incontinence association with obstructive sleep apnea syndrome in a relatively young adult male population. Neurourol Urodyn 2017;36:1804-8.

55. Furukawa S, Sakai T, Niiya T, Miyaoka H, Miyake T, Yamamoto S, et al. Nocturia and prevalence of erectile dysfunction in Japanese patients with type 2 diabetes mellitus: the dogo study. J Diabetes Investig 2016;7: 786-90.

56. Wang TT, Chung MH, Chien HY, Palmer MH, Liao CH, Liao YM. Nocturia in women with type 2 diabetes mellitus: a cross-sectional, correlation study. J Wound Ostomy Continence Nurs 2020;47:265-72.

57. Chung MS, Chuang YC, Lee JJ, Lee WC, Chancellor MB, Liu RT. Prevalence and associated risk factors of nocturia and subsequent mortality in 1,301 patients with type 2 diabetes. Int Urol Nephrol 2014;46:126975.

58. Chang CJ, Pei D, Wu CC, Palmer MH, Su CC, Kuo SF, et al. Correlates of nocturia and relationships of nocturia with sleep quality and glycemic control in women with type 2 diabetes. J Nurs Scholarsh 2017;49: 400-10.

59. Iyer SR. Sleep and type 2 diabetes mellitus- clinical implications. J Assoc Physicians India 2012;60:42-7.

60. Juul KV, Jessen N, Bliwise DL, van der Meulen E, Nørgaard JP. Delaying time to first nocturnal void may have beneficial effects on reducing blood glucose levels. Endocrine 2016;53:722-9.
61. Morris JL, Sereika SM, Houze M, Chasens ER. Effect of nocturia on next-day sedentary activity in adults with type 2 diabetes. Appl Nurs Res 2016;32:44-6.

62. Muraki I, Wada H, Tanigawa T. Sleep apnea and type 2 diabetes. J Diabetes Investig 2018;9:991-7.

63. Reutrakul S, Mokhlesi B. Obstructive sleep apnea and diabetes: a state of the art review. Chest 2017;152:1070-86.

64. Gallegos L, Dharia T, Gadegbeku AB. Effect of continuous positive airway pressure on type 2 diabetes mellitus and glucose metabolism. Hosp Pract (1995) 2014;42:31-7.

65. Zhong W, Tang YG, Zhao X, Go FY, Harper RM, Hui H. Treating obstructive sleep apnea with continuous positive airway pressure benefits type 2 diabetes management. Pancreas 2014;43:325-30.

66. Labarca G, Reyes T, Jorquera J, Dreyse J, Drake L. CPAP in patients with obstructive sleep apnea and type 2 diabetes mellitus: systematic review and meta-analysis. Clin Respir J 2018;12:2361-8.

67. Asplund R, Henriksson S, Johansson S, Isacsson G. Nocturia and depression. BJU Int 2004;93:1253-6.

68. Przydacz M, Skalski M, Golabek T, Sobański JA, Klasa K, Świerkosz A, et al. Nocturia has no impact on depression severity in patients suffering from depression but correlates with sleep quality. Psychiatr Pol 2018;52:835-42.

69. Golabek T, Skalski M, Przydacz M, Świerkosz A, Siwek M, Golabek K, et al. Lower urinary tract symptoms, nocturia and overactive bladder in patients with depression and anxiety. Psychiatr Pol 2016;50:417-30.

70. Asplund R, Johansson S, Henriksson S, Isacsson G. Nocturia, depression and antidepressant medication. BJU Int 2005;95:820-3.

71. Medarov BI, Chaudhry H, Sun JH, Rane N, Judson MA. Effect of SSRIs and SNRIs on nocturnal urinary frequency. Ann Pharmacother 2016;50:471-4.

72. Mun JK, Choi SJ, Kang MR, Hong SB, Joo EY. Sleep and libido in men with obstructive sleep apnea syndrome. Sleep Med 2018;52:158-62.

73. Adams RJ, Appleton SL, Vakulin A, Lang C, Martin SA, Taylor AW, et al. Association of daytime sleepiness with obstructive sleep apnoea and comorbidities varies by sleepiness definition in a population cohort of men. Respirology 2016;21:1314-21. 